\title{
Desvelar o óbvio: o abismo social e educacional na pandemia
}

\author{
Unveil the obvious: the social and educational abyss in pandemic
}

\section{Desvelar lo obvio: el abismo social y educativo en la pandemia}

\author{
Yohana Taise Hoffmann'
}

https://orcid.org/0000-0002-3590-315X

\begin{abstract}
Resumo: Temos como objetivo para este artigo apresentar o cenário educacional e suas perspectivas, dentro de um sistema neoliberal e em meio a uma pandemia. Em um primeiro momento, apresentamos a Constituição Federativa do Brasil de 1988, uma lei fundamental e suprema para todos os brasileiros, a qual possui objetivos para erradicação das desigualdades sociais e garantias para a educação, e, passadas três décadas, ainda essas desigualdades sociais e educacionais estão presentes. Em um segundo momento, descrevemos o contexto educacional brasileiro frente à pandemia, as vulnerabilidades tanto dos estudantes quanto dos professores. Finalizamos o artigo mostrando que pouco mudou nestes anos, desde a Carta Magna de 1988, porém, ressaltando a importância do incentivo e da luta por iniciativas como, por exemplo, a defesa da universalização do acesso à internet neste cenário atual.
\end{abstract}

Palavras-chave: Desigualdade social. Educação. Sociologia da educação.

Abstract: The main aim of this paper is to present the educational scenario and its perspectives, within a neoliberal system and in the midst of a pandemic. First of all, we present the Federative Constitution of Brazil of 1988, a fundamental and supreme law for all Brazilians, which has the objectives to eradicate social inequalities and guarantee education, and how these social and educational inequalities are still present after three decades. Secondly, we present the Brazilian educational context in the face of the pandemic and the vulnerabilities of both students and teachers. We conclude this article by showing that almost nothing has changed in these years since the Constitution, but emphasizing the importance of encouraging and fighting for initiatives, such as the defense of the universalization on internet access in such a current scenario.

Keywords: Social inequality. Education. Sociology of education.

Resumen: Tenemos como objetivo para este artículo, presentar el escenario educativo y sus perspectivas, dentro de un sistema neoliberal y en medio a una pandemia. En un primer momento, presentamos la Constitución Federativa de Brasil de 1988, una ley fundamental y suprema para todos los brasileños, la cual presenta objetivos para la erradicación de las desigualdades sociales y garantías para la educación, y como, pasados tres décadas, sin embargo, estas desigualdades sociales y educativas están presentes. En un segundo momento, presentamos el contexto educativo brasileño frente a la pandemia, las vulnerabilidades tanto de los estudiantes como de los profesores. Finalizamos el artículo probando que poco ha cambiado en estos años, desde la Constitución de

\footnotetext{
' Mestre em Educação Científica e Tecnológica, Universidade Federal de Santa Catarina (UFSC). Doutoranda no Programa de Pós-Graduação em Educação Científica e Tecnológica (PPGECT), Campus Reitor João David Ferreira Lima, R. Eng. Agronômico Andrei Cristian Ferreira, s/n - Trindade, Florianópolis, Santa Catarina, Brasil. 88040-900. E-mail: yohana.thc@gmail.com
}

Olhar de professor, Ponta Grossa, v. 24, p. I-8, e-16I52.06I, 2021.

Disponível em <https://revistas2.uepg.br/index.php/olhardeprofessor> 
1988, pero señalando la importancia del incentivo y la lucha por iniciativas como, por ejemplo, la defensa de la universalización del acceso a Internet en dicho escenario actual.

Palabras-clave: Desigualdad social. Educación. Sociología de la educación.

\section{Apresentar o óbvio}

“[...] a crise educacional do Brasil da qual tanto se fala, não é uma crise, é um programa. Um programa em curso, cujos frutos, amanhã, falarão por si mesmos” (RIBEIRO, 1986, p. 10). Esta citação do sociólogo, antropólogo e educador Darcy Ribeiro, do ano de 1986, mostra o quanto ainda é atual nesse contexto brasileiro que vivemos. Passadas três décadas, o que vemos de diferente? Temos como objetivo, para este artigo, apresentar o cenário educacional e suas perspectivas dentro de um sistema neoliberal e em meio a uma pandemia.

Em um primeiro momento, apresentamos a Constituição Federativa do Brasil de 1988, uma lei fundamental e suprema para todos os brasileiros, a qual possui objetivos para erradicação das desigualdades sociais e garantias para a educação. No segundo momento, expomos o contexto educacional brasileiro frente à pandemia, as vulnerabilidades tanto dos estudantes quanto dos professores, no tópico intitulado "Educação em tempos de crise". Para finalizar, refletimos sobre as mudanças que ocorreram desde a Constituição de 1988 e nos perguntamos: frente a essa realidade tão nefasta, podemos ter alguma esperança? Dessa forma, descrevemos as possíveis mudanças e iniciativas que possam dirimir os abismos sociais e educacionais.

Darcy Ribeiro em seu texto, intitulado "Sobre o óbvio", apresenta dois fatos de nossa sociedade que são evidentes e incontestáveis para a realização desse programa de desigualdades:

Assim é que, desde então, lamentavelmente, já não há como negar dois fatos que ficaram ululantemente óbvios. Primeiro, que não é nas qualidades ou defeitos do povo que está a razão do nosso atraso, mas nas características de nossas classes dominantes, no seu setor dirigente e, inclusive, no seu segmento intelectual. Segundo, que nossa velha classe tem sido altamente capaz na formulação e na execução de projeto de sociedade que melhor corresponde a seus interesses. Só que este projeto para ser implantado e mantido precisa de um povo faminto, chucro e feio (RIBEIRO, 1986, p. 3).

O texto antecede a Constituição da República Federativa do Brasil, aprovada pela Assembleia Nacional Constituinte em 22 de setembro de 1988, e promulgada em 05 de outubro do mesmo ano, tornando-se no processo democrático a lei fundamental e suprema para todos os brasileiros (BRASIL, 1988). Nela destacamos:

\footnotetext{
Art. $3^{\circ}$ - Constituem objetivos fundamentais da República Federativa do Brasil:

I - construir uma sociedade livre, justa e solidária;

II - garantir o desenvolvimento nacional;

III - erradicar a pobreza e a marginalização e reduzir as desigualdades sociais e regionais;
}

Olhar de professor, Ponta Grossa, v. 24, p. I-8, e-16152.06I, 202I.

Disponível em <https://revistas2.uepg.br/index.php/olhardeprofessor> 
IV - promover o bem de todos, sem preconceitos de origem, raça, sexo, cor, idade e quaisquer outras formas de discriminação (BRASIL, 1988).

Podemos observar que os objetivos são legítimos, porém, os desafios são notáveis. Segundo Garcia e Hillesheim (2017), houve iniciativas como a Lei n. 13.005/20 I4, que apresenta diretrizes para superação das desigualdades educacionais, promovendo a cidadania e erradicando todas as formas de discriminação, ampliando o acesso da participação desses segmentos populacionais historicamente discriminados, oportunizando "acesso à política educacional em todos os níveis de formação (indígenas, quilombolas, negros etc.), acabam sendo neutralizados com a adoção de uma lógica de avaliação baseada na meritocracia e no ranqueamento" (GARCIA; HILLESHEIM, 20I7, p. I38).

Dessa forma, para atingir os objetivos propostos na Constituição de 1988, principalmente a erradicação da pobreza e das desigualdades sociais, os autores Garcia e Hillesheim (2017) mencionam - Plano Brasil Sem Miséria, entre outros projetos, "buscando aprofundar o processo de redução das desigualdades por meio das políticas de transferência de renda, valorização do salário mínimo, expansão dos postos de trabalhos formais e inclusão produtiva" (p. 137). O Plano Brasil Sem Miséria visa incorporar um número maior de brasileiros ao mercado interno e, dessa forma, possibilita a garantia tanto da produção quanto do consumo. As ações que se destacaram foram as relacionadas ao Programa Nacional de Acesso ao Ensino Técnico e Emprego (Pronatec), ao Programa Crescer e à Economia Solidária (GARCIA; HILLESHEIM, 20I7).

Os direitos e garantias fundamentais voltados à educação estão presentes no "Art. $6^{\circ}$ : São direitos sociais a educação, a saúde, a alimentação, o trabalho, a moradia, o transporte, o lazer, a segurança, a previdência social, a proteção à maternidade e à infância, a assistência aos desamparados, na forma desta Constituição" (BRASIL, 1988). A redação foi atualizada pela Emenda Constitucional n. 90, de 2015. No entanto, esses direitos ainda não estão garantidos, como podemos observar:

\footnotetext{
A despeito do direito à moradia estar entre os direitos fundamentais (Art. 6, Constituição Federal), o déficit de moradias ultrapassa 7,7 milhões, compreendendo que mais de 3,3 milhões estão com extrema dificuldade de pagar o aluguel $(91 \%$ do déficit está situado em famílias com renda de até 3 salários mínimos), situação que se agrava no atual contexto de pandemia. Outros 3,2 milhões de habitações são divididas por famílias distintas que ocupam o mesmo teto, 950 mil habitações estão em estado de completa precariedade e outras 320 mil estão em situação de extremo adensamento (COLERMAX, 2020, p. 15).
}

A pesquisa de Silva (2020) apresenta a ampliação da obrigatoriedade escolar, assim como a relação histórica entre inclusão e exclusão. De acordo com a autora, a "desigual inclusão nos níveis escolares, bem como sua distribuição pelo território brasileiro e entre classes sociais e raça/etnia, compõe um quadro histórico de afirmação/negação do direito à Educação” (SILVA, 2020, p. 286).

Olhar de professor, Ponta Grossa, v. 24, p. I-8, e-16152.06I, 2021.

Disponível em <https://revistas2.uepg.br/index.php/olhardeprofessor> 
A autora, ao mencionar a reforma realizada pela Lei $n$. 13.4/5/17, divulga o resultado de disputas acerca das finalidades e forma de organização do Ensino Médio dos últimos 20 anos. Silva (2020), relata que essas mudanças se devem ao maior acesso da juventude na etapa final da Educação Básica brasileira. Afirma, ainda, que o Ministério da Educação, com a criação do Programa Ensino Médio Inovador (ProEMI), buscava a reformulação curricular nas redes estaduais, "além dos documentos orientadores das avaliações nacionais, que culminaram por incidir, também, na organização curricular das escolas" (SILVA, 2020, p. 287). E conclui, apontando que os "impactos dessas alterações no cenário da obrigação do Estado em assegurar a efetiva ampliação do acesso, fez emergir novos pontos de tensão e de constrangimento diante de um direito proclamado, mas ainda distante de ser realizado" (SILVA, 2020, p. 287).

A gratuidade da educação só foi plenamente assegurada na Constituição de 1988, ao passo que a obrigatoriedade do ensino, dos 4 aos 17 anos, apenas em 2016. Dessa forma, podemos elencar o acesso, a qualidade e a equidade do ensino como pontos ainda a serem discutidos, e que estão longe de uma resolução.

\section{Educação em tempos de crise}

Como referimos anteriormente, os abismos sociais já se fazem presentes em nossa sociedade muito antes da chegada da pandemia. Santos (2020), no texto "Vírus: Tudo o que é sólido desmancha no ar", parafraseando a célebre frase de Marx, apresenta as mazelas do mundo neoliberal e anuncia nas primeiras páginas, que "a pandemia vem apenas agravar uma situação de crise a que a população mundial tem vindo a ser sujeita" (SANTOS, 2020, p. 46).

Este autor faz uma reflexão entre o embate econômico, social e cultural entre a China e os EUA, e finaliza o texto mencionando a "sociologia das ausências", de como será difícil enfrentarmos esse vírus em uma realidade tão dura, até mesmo para a Europa, ao mencionar os refugiados, por exemplo: "Num desses campos (campo de Moria) há uma torneira de água para 1300 pessoas e falta sabão. Os internados não podem viver senão colados uns aos outros. Famílias de cinco ou seis pessoas dormem num espaço com menos de três metros quadrados" (SANTOS, 2020, p. 49). Podemos associar essa situação a inúmeros brasileiros que vivem em situação de miserabilidade, como vimos anteriormente, mas o autor continua: "Isto também é Europa - a Europa invisível” (SANTOS, 2020, p. 49).

O que essa pandemia vem desvelar é esse "capitalismo selvagem". Segundo Chomsky (2020), desde o ano de 2003, ao mencionar a SARS (síndrome respiratória aguda grave), já havia pesquisas para realizar estudos para uma pré-vacina e evitar esse novo vírus. No entanto, dentro do sistema que

Olhar de professor, Ponta Grossa, v. 24, p. I-8, e-16152.06I, 2021.

Disponível em <https://revistas2.uepg.br/index.php/olhardeprofessor> 
vivemos, os "sinais do mercado eram claros: não há lucro em evitar uma catástrofe futura" (CHOMSKY, 2020, p. 153).

Estamos vivendo em um momento de desvalorização da ciência e, principalmente, das ciências sociais, em particular, da educação. As discussões relacionadas às aulas remotas e à realização do Exame Nacional do Ensino Médio (Enem) escarnam o abismo da sociedade brasileira.

Nesse contexto, a escola pública tem sido o alvo principal da propaganda de desqualificação, contingenciamento de recursos, bem como a inibição de investimento público e incentivo às iniciativas de escolas charter, vouchers e propostas de homeschool, crescendo em uma progressiva onda de políticas de Estado mínimo, reverberadas constantemente por mass media (VENTURA, 2020, p. 2).

Cabe destacar que, neste cenário de pandemia, as medidas que estão sendo tomadas no âmbito da educação são aulas remotas, isto é, uma modalidade diferente do ensino à distância ( $E a D)$, na qual envolvem a formação de professores, uma estrutura institucional, cronogramas, um ambiente virtual de ensino e aprendizagem e práticas pedagógicas mediadas pelas tecnologias da informação e comunicação (TICs). De acordo com o coletivo COLEMARX (2020), na rede pública "inexistem práticas pedagógicas mediadas pelas TICs estabelecidas de modo universal" (COLEMARX, 2020, p. 17). Os autores apresentam os dados da educação básica brasileira e como se dá o acesso à internet nas escolas:

A Educação Básica brasileira comporta 47,9 milhões de matrículas e 2,2 milhões de docentes em 180,6 mil escolas. As escolas públicas brasileiras não universalizaram o acesso à internet para seus estudantes e, tampouco, para o uso administrativo. Segundo dados do Censo Escolar de 2019, apenas 29,1\% dos alunos do ensino fundamental e 61,9\% do ensino médio da Rede Pública têm acesso à internet em suas escolas. Para ações de ensino e aprendizagem, são $37,2 \%$ e $66,2 \%$ respectivamente (INEP, 2020) (COLEMARX, 2020, p. I7).

O que observamos neste momento são diversos estudantes da rede pública de ensino que não possuem o mínimo para a sua subsistência, ou seja, a internet como a ferramenta que irá proporcionar o acesso às informações se torna secundária em um contexto em que os estudantes não possuem comida em seus lares. No entanto, como as escolas estão fechadas, temos uma perspectiva: foi sancionada a Lei n. 13.987/20, no dia 07 de abril de 2020, que garante a distribuição dos alimentos da merenda escolar às famílias dos estudantes da educação básica da rede pública, cujas aulas foram suspensas devido à pandemia (BRASIL, 2020).

Assim como os estudantes estão em situações de vulnerabilidade, muitos professores vivenciam realidades semelhantes, entre elas a baixa remuneração e a contratação em caráter temporário. 
Em 2017, aproximadamente 42\% dos professores da Educação Básica pública não tinham estabilidade no emprego, sendo que, destes, 299.673 (14\%) eram voluntários e 565.538 (27\%) temporários e I\% tinha contrato CLT. Em torno de 65\% desses professores trabalham 40 horas semanais ou mais; $43 \%$ em duas ou mais escolas, e $34 \%$ deles não têm seu horário de planejamento de aulas respeitado (ao menos um terço da carga horária contratual, nos termos da LDB). Desse modo, as consequências do isolamento social são especialmente penosas não somente para os estudantes, mas também para muitos trabalhadores da educação (COLEMARX, 2020, p. 17-18).

Além da instabilidade e o aumento das horas semanais de trabalho, no contexto da pandemia, o Instituto Península (2020) realizou uma pesquisa com 7.773 respondentes, entre professores da educação básica, tanto da rede privada quanto pública, em todos os níveis de ensino, incluindo diferentes modalidades, como a Educação de Jovens e Adultos (EJA). A pesquisa está no estágio dois, intermediário, entre duas e seis semanas após a suspensão das aulas presenciais, e aponta alguns resultados em relação às rotinas e aos hábitos dos docentes.

Destacamos os seguintes resultados: em relação ao sentimento dos professores, nas últimas semanas "ansiosos (67\%), entediados (36\%), cansados (38\%), estressados (34\%), sobrecarregados (35\%), frustrados (27\%)" (INSTITUTO PENÍNSULA, 2020, p. 9). Podemos associar esses sentimentos à falta de preparo e formação em relação ao ensino virtual. "Antes da paralisação das aulas presenciais, $88 \%$ dos professores nunca tinha dado aula à distância de forma remota. Dessa forma, a grande maioria dos professores $(83,4 \%)$ se sente nada ou pouco preparados para ensinar de forma remota" (INSTITUTO PENÍNSULA, 2020, p. I4). Assim como a falta das ações das escolas, podemos observar: "Além de estarem preocupados e não se sentirem preparados para o ensino virtual/online, a maioria dos professores declara que até o momento não recebeu apoio emocional nem treinamento para ensinar à distância" (INSTITUTO PENÍNSULA, 2020, p. 17).

Outro fator que os professores se depararam nesse novo cenário de isolamento social é lidar com os dispositivos que possuem para trabalhar. "Apesar da maioria dos professores possuir celular e notebook para trabalhar de casa, chama atenção o alto percentual de professores que precisam compartilhar seus equipamentos com a família” (INSTITUTO PENÍNSULA, 2020, p. 22). Assim como as jornadas de trabalho, que aumentaram: "A rotina dos docentes passou a ser ocupada por mais atividades domésticas (66\%), o trabalho de casa nas atividades das escolas (62\%) e estudos (50\%)" (INSTITUTO PENÍNSULA, 2020, p. 24).

\section{À guisa de algumas reflexões}

"A escola pública, laica, universal e obrigatória, que tem a duras penas resistido ao processo de desqualificação neoliberalizante e neoconservador, ainda é um desses lugares tradicionais de construção de experiências pelos encontros intergeracionais e interclasses que promove" (VENTURA,

Olhar de professor, Ponta Grossa, v. 24, p. I-8, e-16152.06I, 2021.

Disponível em <https://revistas2.uepg.br/index.php/olhardeprofessor> 
2020, p. 15). Estaremos sempre defendendo a educação pública, de qualidade e gratuita. O que estamos vivendo, neste contexto de pandemia, não se pode comparar com $\mathrm{EaD}$, que possui um ideário social de política pública para ampliar o acesso ao ensino superior no país. Entretanto, o que vemos são aulas remotas extremamente excludentes, com o controle do capital pelos grandes grupos e corporações privadas, uma ampliação da exclusão. Dessa forma, é importante incentivar e lutar por iniciativas como a defesa da universalização do acesso à internet, por exemplo:

Defende-se que, no século $X X I$, o acesso à internet é um direito fundamental, a exemplo dos direitos, ainda não assegurados, à água potável, à rede de esgoto, à energia, ao transporte. Considerando as crianças e jovens, esse direito é ainda mais urgente e deve ser assegurado pelo Estado, por se tratar de um serviço de crucial relevância. Complementarmente, os meios tecnológicos para interação criativa na internet devem ser popularizados e assegurados para todos os estudantes, especialmente computadores portáteis de qualidade (COLEMARX, 2020, p. 8).

Além de desvelar o óbvio, como podemos pensar em medidas para dirimir as desigualdades sociais? Infelizmente, o texto de Darcy Ribeiro (1986) ainda é atual. Frente a essa realidade tão nefasta, podemos ter alguma esperança? A luta para garantir os direitos fundamentais, em um Estado Democrático de Direito no qual vivemos, é constante. Assim, temos que pensar em uma nova agenda, em novos objetivos, em novas estratégias, sem perder a esperança por tempos melhores.

E tentarmos construir uma sociedade livre, justa e solidária para que, juntos, possamos garantir o desenvolvimento nacional. Talvez, então, emanados num mesmo sentimento, o da esperança, consigamos erradicar a pobreza e a marginalização e reduzir as desigualdades sociais e regionais, promovendo o bem de todos, sem termos preconceitos de origem, raça, sexo, cor, idade e quaisquer outras formas de discriminação como prevê a Carta Magna do Brasil.

\section{Referências}

BRASIL. [Constituição (1988)]. Constituição da República Federativa do Brasil: promulgada em 5 de outubro de 1988. Disponível em: http://www.planalto.gov.br/ccivil_03/constituicao/constituicao.htm. Acesso em: 07 mai. 2020.

BRASIL. Lei n. 13.987 de 07 de abril de 2020. Altera a Lei $n^{\circ}$ II.947, de 16 de junho de 2009, para autorizar, em caráter excepcional, durante o período de suspensão das aulas em razão de situação de emergência ou calamidade pública, a distribuição de gêneros alimentícios adquiridos com recursos do Programa Nacional de Alimentação Escolar (Pnae) aos pais ou responsáveis dos estudantes das escolas públicas de educação básica. Diário Oficial da União, Brasília, 07 abr. 2020. Disponível em: https://www2.camara.leg.br/legin/fed/lei/2020/lei- I 3987-7-abril-2020-789956-publicacaooriginalI6029I-pl.html. Acesso em: 07 mai. 2020.

CHOMSKY, N. Capitalismo selvagem e a sobrevivência da humanidade. In: TOSTES, A.; MELO FILHO, H. Quarentena: reflexões sobre a pandemia e depois. I.ed. Bauru: Canal 6 (Projeto Editorial Praxis), 2020. p. 152-16I. 
COLEMARX, Coletivo de Estudos em Marxismo e Educação. Em defesa da educação pública comprometida com a igualdade social: porque os trabalhadores não devem aceitar aulas remotas. Rio de Janeiro: Programa de Pós-Graduação em Educação, abr. 2020. Disponível em: https://observatoriocondicoesvidaetrabalho.files.wordpress.com/2020/05/colemarx-texto-crc3adticoead-2.pdf. Acesso em: 07 mai. 2020.

GARCIA, A. V.; HILLESHEIM, J. Pobreza e desigualdades educacionais: uma análise com base nos Planos Nacionais de Educação e nos Planos Plurianuais Federais. Educar em revista, Curitiba, n. spe.2, p. I3I-I47, set. 2017. Disponível em: https://doi.org/I 0.1590/0 I04-4060.5 I386. Acesso em: 07 mai. 2020.

INSTITUTO PENÍNSULA. Relatório de Pesquisa: Sentimento e percepção dos professores brasileiros nos diferentes estágios do Coronavírus no Brasil. Disponível em:

https://institutopeninsula.org.br/wp-

content/uploads/2020/05/CovidI9_InstitutoPeninsula_Fase2_at\%C3\%A91405.pdf. Acesso em: I4 Mai. 2020.

RIBEIRO, D. Sobre o óbvio: ensaios insólitos. Rio de Janeiro, Editora Guanabara, 1986.

SANTOS, B. S. Vírus: Tudo o que é sólido desmancha no ar. In: TOSTES, A.; MELO FILHO, H. Quarentena: reflexões sobre a pandemia e depois. I.ed. Bauru: Canal 6 (Projeto Editorial Praxis), 2020. p. 45-49.

SILVA, M. R. Ampliação da obrigatoriedade escolar no Brasil: o que aconteceu com o Ensino Médio? Ensaio: avaliação e políticas públicas em Educação, Rio de Janeiro, v. 28, n. 107, p. 274-29I, jun. 2020. Disponível em: https://doi.org/I0.1590/S0I04-40362019002701953. Acesso em: 07 mai. 2020.

VENTURA, L. Homeschooling ou a educação sitiada no intèrieur: notas a partir de Walter Benjamin. Práxis Educativa, Ponta Grossa, v. 15, e20148I5, p. I-18, 2020. Disponível em: https://www.redalyc.org/jatsRepo/894/89462860062/html/index.html. Acesso em: 07 mai. 2020.

Recebido em: 16 de junho de 2020.

Versão corrigida recebida em: 10 de maio de 2021.

Aceito em: 10 de maio de 2021 .

Publicado online em: II de junho de 2021 .

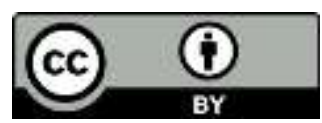

Olhar de professor, Ponta Grossa, v. 24, p. I-8, e-16152.06I, 2021.

Disponível em <https://revistas2.uepg.br/index.php/olhardeprofessor> 